primary care. In view of the wide variation in positivity by locality, it is likely testing for TV will be cost effective in some areas. Ongoing surveillance may be necessary to identify those at risk.

\section{O30 SERVICE PROVISION AND ECONOMIC IMPLICATIONS OF IMPLEMENTING NAAT TESTS FOR TRICHOMONAS VAGINALIS IN WOMEN ATTENDING GENITOURINARY MEDICINE CLINICS AND PRIMARY CARE}

${ }^{1}$ Katy Turner*, ${ }^{2}$ Jane Nicholls, ${ }^{3}$ Peter Muir, ${ }^{1}$ Margaret May, ${ }^{2}$ Paul North, ${ }^{1} J o h n$ Macleod, ${ }^{1}$ Paddy Horner. ' University of Bristol, Bristol, UK; ${ }^{2}$ Bristol Sexual Health Clinic, Bristol, UK;

${ }^{3}$ Public Health England, Bristol, UK

10.1136/sextrans-2015-052126.30

Background/introduction Laboratory tests for Trichomonas vaginalis using culture and microscopy in current practice have low sensitivity, however new, highly sensitive PCR-based nucleic acid amplification tests (TV NAATs) have been approved e.g. Aptima TV NAAT. It is not known how to optimally deploy these new tests in different settings.

Aim(s)/objectives To assess the cost-effectiveness of new TV NAAT tests for the diagnosis of TV infection in women attending genitourinary medicine (GUM) and primary care clinics. To inform national decision-making about who should be offered TV testing.

Methods We analysed data from TV tests in residual chlamydia/ gonorrhoea samples from nearly 9,000 women. We conducted notes review in GUM clinics to understand current practice. We compared current and proposed pathways for management of TV. We calculated the cost of testing for TV in GUM and primary care.

Results Table 1 shows the breakdown of test results by symptomatic/asymptomatic and setting and indicates the current and new cost of testing. (NB. Provisional data, study closed 31/1/ 2015). Compared with current testing practice, TV NAAT testing detected an additional 41 cases from GUM. In primary care few samples were sent for laboratory testing; only 15 out of 126 NAAT positive cases would have been detected.

Discussion/conclusion TV NAAT tests detected many more infections than current testing. Nationally, this translates to an increase in GUM from 6,000 cases to 23,400 cases annually. Overall, the crude cost of adding TV NAAT testing to all chlamydia and gonorrhoea tests is $£ 307$ per additional infection diagnosed.

\section{MENSES - TO TEST OR NOT TO TEST?}

${ }^{1}$ Sarah Schoeman*, ${ }^{2}$ Catherine Stewart, ${ }^{1}$ Janet Wilson. 'Leeds Teaching Hospitals Trust, Leeds, UK; ${ }^{2}$ Salford Royal Foundation Trust, Manchester, UK

10.1136/sextrans-2015-052126.31
Background/introduction Varied advice is given to women about testing for chlamydia (CT) and gonorrhoea (NG) whilst menstruating. Some are advised it makes no difference, others are advised not to test or are offered urine sampling instead of a vulvovaginal swab. There is no published evidence to inform such advice.

Aim(s)/objectives To determine if menses affects the performance of CT/NG NAATs.

Methods Using data collected in a large CT/NG NAATs diagnostic study we compared the prevalence of infections in menstruating women versus those not menstruating.

Results Of the 3973 study participants 162 (4\%) were menstruating and 3811 were not. 30 (18.5\%) menstruating women had CT and 10 (6.2\%) had NG; 380 (10\%) non-menstruating women had CT and 90 (2.4\%) had NG. Menstruating women were more likely to be diagnosed with CT (OR 2.05; $\mathrm{p}=$ 0.0008 ) and NG (OR 2.72; $\mathrm{p}=0.0055)$; less likely to have had a previous STI (OR 0.66) and to have cervicitis (OR 0.21) but more likely to be a STI contact (OR 2.13) and have bacterial STI symptoms (OR 1.36). After adjusting for these confounding variables menstruating women remained more likely to be diagnosed with CT (Adjusted OR 1.98; 95\% CI 1.27-3.09; $\mathrm{p}=0.003$ )

Discussion/conclusion Menses does not have a negative effect of the performance of CT/NG NAATs; in fact the prevalence of infections was higher in menstruating women. Only $4 \%$ of women were menstruating suggesting that women avoid attending for STI testing during their period unless really necessary. Hence testing should be performed during menstruation using vulvovaginal or endocervical swabs.

\section{ASYMPTOMATIC NEUROSYPHILIS IS UNLIKELY IN HIV INFECTED PATIENTS AFTER TREATMENT FOR EARLY SYPHILIS WITH BENZATHINE PENICILLIN G}

Andrew Tomkins*, Shazaad Ahmad, Darren E Cousins, Francisco Javier Vilar, Stephen P Higgins. North Manchester General Hospital, Manchester, UK

\subsection{6/sextrans-2015-052126.32}

Background/introduction Benzathine penicillin G (BPG) does not cross the blood-brain barrier. Some experts believe that BPG may be ineffective when treating patients co-infected with HIV and syphilis.

$\operatorname{Aim}(\mathrm{s}) /$ objectives To establish the risk of asymptomatic neurosyphilis (ANS) after treatment of early syphilis in HIV positive patients with single dose BPG.

Methods HIV patients with early syphilis were offered a posttreatment lumbar puncture if their CD4 count was $<350$ and/or their serum RPR $>16$. Patients with clinical neurosyphilis were excluded. ANS was defined as a positive CSF RPR, or CSF white blood cells $>20 / \mathrm{mm}^{3}$ plus CSF TPPA $>1: 320$

\begin{tabular}{|c|c|c|c|c|c|c|c|c|}
\hline & & Positive (current) & Negative & Total (current) & Positivity & Current cost & New cost & $\begin{array}{l}\text { Cost per } \\
\text { extra case }\end{array}$ \\
\hline \multirow[t]{2}{*}{ Genitourinary medicine } & Symptomatic & $22(9)$ & 497 & $519(440)$ & $4.2 \%$ & $€ 3,489$ & f3,955 & f35.8 \\
\hline & Asymptomatic & $28(0)$ & 1571 & $1599(0)$ & $1.8 \%$ & f0 & $\mathrm{f} 12,184$ & $£ 435.2$ \\
\hline \multirow[t]{2}{*}{ Primary care } & Symptomatic & $86(13)$ & 3185 & $3271(1651)$ & $2.6 \%$ & $f 13,092$ & $£ 24,925$ & f162.1 \\
\hline & Asymptomatic & $40(2)$ & 3405 & $3445(497)$ & $1.2 \%$ & $\mathrm{f} 3,941$ & $\mathrm{f} 26,251$ & f587.1 \\
\hline Total & & $176(24)$ & 8658 & $8834(2588)$ & $2.0 \%$ & $£ 20,523$ & $\mathrm{f} 67,315$ & $\mathrm{f} 307.8$ \\
\hline
\end{tabular}

